\begin{tabular}{|l|l|l||}
\hline \multicolumn{2}{|c|}{ PublisherInfo } \\
\hline \hline PublisherName & $:$ & BioMed Central \\
\hline \hline PublisherLocation & $:$ & London \\
\hline \hline PublisherImprintName & $:$ & BioMed Central \\
\hline \hline
\end{tabular}

\title{
Liposomal doxorubicin in metastatic breast cancer
}

\begin{tabular}{|l|l|l||}
\hline \multicolumn{2}{|c|}{ ArticleInfo } \\
\hline \hline ArticleID & $:$ & 3651 \\
\hline \hline ArticleDOI & $:$ & $10.1186 /$ bcr-1999-66629 \\
\hline \hline ArticleCitationID & $:$ & 66629 \\
\hline \hline ArticleSequenceNumber & $:$ & 17 \\
\hline \hline ArticleCategory & $:$ & Paper Report \\
\hline ArticleFirstPage & $:$ & 1 \\
\hline \hline ArticleLastPage & $:$ & 4 \\
\hline \hline & & RegistrationDate : 1999-6-10 \\
\hline ArticleHistory & $:$ & OnlineDate \\
\hline \hline ArticleCopyright & $:$ & Current Science Ltd1999-6-10 \\
\hline \hline ArticleGrants & $:$ & \\
\hline \hline ArticleContext & $:$ & 1305822 \\
\hline \hline
\end{tabular}




\section{Keywords}

metastatic breast cancer, liposomal doxorubicin, phase II

\section{Introduction}

Doxorubicin is the most commonly used anthracycline drug in the treatment of breast cancer. It is highly active either as a single agent or as a component of combination regimens in both the adjuvant and the metastatic setting. Unfortunately, it can cause life-threatening cardiomyopathy at cumulative doses above $450-500 \mathrm{mg} / \mathrm{m}^{2}$. The risk of cardiac damage is related both to the cumulative dose and to peak drug level. Efforts to reduce cardiac toxicity include prolonged infusional schedules and adding dexrazoxane (a cardioprotective agent) to the schedule. Another method of reducing toxicity is the use of liposomes which can encapsulate the doxorubicin, concentrate in tissues rich with reticuloendothelial cells and unload the doxorubicin across specific $\mathrm{pH}$ gradients, which are more likely to be present in tumor tissue than in normal tissues. Thus, liposome-encapsulated doxorubicin offers the possibility of increased targeting of the drug to the tumor with reduced cardiac toxicity.

\section{Aims}

To study the efficacy and safety profile (in particular, cardiac toxicity) of a chemotherapy regimen consisting of liposome-encapsulated doxorubicin (TLC D-99), fluorouracil (5-FU), and cyclophosphamide as first-line treatment in patients with metastatic breast cancer (MBC).

\section{Comments}

Although this study was small, it appears that liposomal encapsulation of doxorubicin has great potential for treatment of breast cancer. This technique appears to have no detrimental effect on the antitumor efficacy of doxorubicin, whilst causing less cardiac toxicity. Thus, liposomal doxorubicin probably has a better therapeutic index than free doxorubicin. Phase III prospective randomised trials are needed to confirm the results of this study. If the confirmed, then rapid incorporation of liposomal doxorubicin into regimens with significant risks of cardiac toxicity (ie paclitaxel + doxorubicin, doxorubicin + Her2-neu antibody) can be anticipated. 


\section{Methods}

A total of 41 women were entered into the study; all patients had measurable disease and no previous chemotherapy for MBC. Patients were required to have a baseline left ventricular ejection fraction (LVEF) of $>50 \%$. The treatment schedule consisted of TLC D-99 $60 \mathrm{mg} / \mathrm{m}^{2}$ and cyclophosphamide 500 $\mathrm{mg} / \mathrm{m}^{2}$ on day 1 and 5-FU $500 \mathrm{mg} / \mathrm{m}^{2}$ on days 1 and 8 every 3 weeks. Dose levels could be increased or decreased according to strict toxicity criteria. LVEF was measured every three cycles and endocardial biopsies were performed according to protocol-defined criteria.

\section{Results}

The 41 patients were a young, fit group with minimal prior chemotherapy exposure (17\%). The median number of liposomal-doxorubicin cycles administered per patient was 10 (range 2-18), and a median cumulative dose of $528 \mathrm{mg} / \mathrm{m}^{2}$ (range $108-962 \mathrm{mg} / \mathrm{m}^{2}$ ) was given. Twenty-one patients reached a cumulative doxorubicin dose greater than $500 \mathrm{mg} / \mathrm{m}^{2}$. The overall response rate was $73 \%$ (95\% confidence interval, $57-86 \%$ ), with two patients (5\%) achieving a complete response. The median duration of response was 11.2 months (3.9 - 34 months), the median time to treatment failure was 8.1 months (1.6 - 34 months), and the median overall survival duration was 19.4 months (4.2 - 54 months).

The most common toxicity was myelosuppression, with $42 \%$ of cycles resulting in a neutrophil count $<500 /$ ul. Neutropenic fever requiring intravenous antibiotics occurred in $6 \%$ of cycles. A total of $26 \%$ of cycles required a dose delay of $>5$ days and $34 \%$ required a dose reduction. A dose increase was only possible in $6 \%$ of cycles. Non-hematological toxicity was generally mild as was cardiac toxicity. The median change in LVEF was -4 (range -42 to +14 ). Only four patients stopped treatment due to cardiac events. Two patients stopped due to a decrease in LVEF to U 40\%, and one because her endomyocardial biopsy result was grade 1.5 (modified Billingham scale).

\section{Discussion}

This phase II study showed that the regimen was highly active with comparable response rates and survival figures to studies of the same regimen which included free doxorubicin. Toxicity was generally as expected, although a quarter of the patients did develop neutropenic fever at some point in their treatment. Clinical cardiac events were few, and the incidence of cardiac failure was much lower than that expected if similar cumulative doses of free doxorubicin had been given. Subclinical cardiac toxicity was also rare. 


\section{References}

1. Valero V, Buzdar AU, Theriault RL, Azarnia N, Fonseca GA, Willey J, Ewer M, Walters RS, Mackay B, Podoloff D, Booser D, Lee LW, Hortobagyi GN: Phase II trial of liposome encapsulated doxorubicin, fluorouracil, and cyclophosphamide as first-line therapy in patients with metastatic breast cancer. J Clin Oncol. 1999, 15: 1425-1434. 